\title{
A Nova Gestão Pública no contexto escolar e os dilemas dos(as) diretores(as)
}

\author{
The New Public Management in the school context and the \\ dilemmas of the principals \\ La Nueva Gestión Pública en el contexto escolar y los \\ dilemas de los/las directores(as) \\ DALILA ANDRADE OLIVEIRA \\ ALEXANDRE WILLIAM BARBOSA DUARTE \\ ANA MARIA CLEMENTINO
}

\begin{abstract}
Resumo: $\mathrm{O}$ artigo apresenta resultados de pesquisa que tem como foco a percepção das direções escolares sobre as mudanças ocorridas nos últimos anos na gestão e na organização da escola. Nas últimas décadas, as políticas públicas em educação no Brasil vêm sofrendo importante mudança de paradigma, que busca reorientar os objetivos, os processos de trabalho e as finalidades das escolas públicas. Essas políticas têm imposto uma regulação centrada na avaliação externa como parâmetro para medir a eficiência da gestão escolar, da qual depende seu financiamento. Essa regulação encontra seu fundamento na Nova Gestão Pública (NGP).
\end{abstract}

Palavras-chave: Gestão Escolar; Diretor Escolar; Nova Gestão Pública.

Abstract: The article presents the results of a research that focus on the school principals' perception of the changes that have occurred in recent years in the management and organization of the school. In the last decades, the public policies in education in Brazil have undergone an important paradigm shift that seeks to reorient the goals, the work processes, and the purposes of public schools. These policies have imposed a regulation centered on the external evaluation as a parameter to measure the efficiency of the school management, on which its financing depends. This regulation is based on the New Public Management (NPM).

Keywords: School Management; School Director; New Public Management.

Resumen: El artículo presenta resultados de investigación que tienen como foco la percepción de los directores de escuelas sobre los cambios ocurridos en los últimos años en la gestión y organización de la escuela. En las últimas décadas, las políticas públicas en educación en Brasil vienen sufriendo un importante cambio de paradigma que busca reorientar los objetivos, los procesos de trabajo y las finalidades de las escuelas públicas Estas políticas han impuesto una regulación centrada en la evaluación externa como parámetro para medir la eficiencia de la gestión escolar, de la cual depende su financiación. Esta regulación encuentra su fundamento en la Nueva Gestión Pública (NGP).

Palabras clave: Gestión Escolar; Director Escolar; Nueva Gestión Pública. 


\section{INTRODUÇÃO}

Este artigo apresenta resultados de pesquisa ${ }^{1}$ que teve como objetivo "identificar e analisar consequências sobre a organização e gestão escolar resultantes da mudança de paradigma nas políticas públicas para a Educação Básica nas últimas décadas". O texto parte da constatação de que, nas últimas décadas, as políticas públicas em educação no Brasil vêm sofrendo importante mudança de paradigma que busca reorientar os objetivos, os processos de trabalho e as finalidades das escolas públicas². O marco histórico dessa mudança é a Constituição Federal de 1988, que, ao promover o fortalecimento dos governos locais como resultado das pressões de movimentos que demandavam maior descentralização e redemocratização da sociedade, acabou ensejando novos modelos de gestão das políticas públicas no país. O contexto é ainda influenciado por variáveis externas que se relacionam com a circulação de políticas e conhecimento em âmbito internacional aos quais o Brasil não está imune. Essas influências são absorvidas no plano interno como um movimento mais amplo que cobra do Estado e de suas instituições maior transparência e prestação de contas.

Os resultados analisados neste artigo têm como foco as mudanças ocorridas na realidade escolar brasileira com as reformas educacionais iniciadas nos anos 1990, com consequências sobre a organização do trabalho na escola. A partir de revisão de literatura, constatou-se nova regulação nas políticas educativas que tem interferido na organização e gestão da educação, passando pelas várias mediações dos sistemas educacionais, mas com forte acento na escola. Essa regulação tem forte centralidade na avaliação externa, articulando seus resultados à gestão escolar e ao financiamento da educação, e encontra seu fundamento na Nova Gestão Pública (NGP).

A partir da primeira década do século XXI, o país presenciou mudanças no curso das políticas públicas sociais, incluindo a educação, que promoveram verdadeira revolução no sentido de incluir socialmente setores que historicamente estiveram excluídos de espaços sociais importantes, entre os quais o sistema escolar (OLIVEIRA, 2015). As escolas públicas desempenharam papel fundamental nesse processo, acolhendo segmentos populacionais que, pela primeira vez, passaram a ter acesso à educação e a outros benefícios sociais.

1 Autonomia e responsabilização no contexto escolar: os desafios para os diretores frente às exigências de justiça social e eficiência educativa, desenvolvida entre os anos de 2013 e 2017, com o apoio do CNPq, por meio do Edital Universal 2013. da Secretaria de Educação Básica do Ministério da Educação (SEB/MEC) e do Programa Pesquisador Mineiro da Fundação de Amparo à Pesquisa do Estado de Minas Gerais.

2 A pesquisa Trabalho docente na Educação Básica no Brasil-TDEBB . 
A questão principal do artigo é discutir como as orientações emanadas dos princípios da NGP chegam à escola e como, na percepção dos (as) diretores (as) escolares quando falam de sua prática o exercício do cargo, convivem com políticas inclusivas.

Os resultados analisados referem-se à percepção dos (as) diretores (as) em relação a essas políticas, no intuito de compreender como esses sujeitos têm lidado com novas demandas sociais que chegam às escolas e com as orientações emanadas dos órgãos superiores, que se centram nas metas de resultados. Para tanto, elegeram-se como amostra cinco capitais de estados das distintas regiões geográficas do país, sendo elas: Belo Horizonte, Goiânia, Curitiba, Recife e Belém. Em cada uma das capitais mencionadas, foram realizadas entrevistas semiestruturadas com diretores (as) de escolas da Educação Básica. Foram selecionadas cinco unidades educacionais (UE) em cada capital, atendendo às distintas etapas (Educação Infantil, Ensino Fundamental e Ensino Médio) e redes de ensino da Educação Básica (estadual e municipal).

As entrevistas foram precedidas de levantamento documental e de dados estatísticos sobre a política educacional em cada estado e capital, recolhendo informações fundamentais para a análise das entrevistas.

Este artigo pretende explorar algumas questões abordadas nas entrevistas, tendo como referência o contexto das escolas públicas brasileiras e sua variedade em cada região e estado do país, buscando analisar qual a percepção dos(as) diretores(as) sobre as exigências que chegam às escolas. Para tanto, considera-se indispensável uma rápida discussão sobre os fundamentos da NGP e seu percurso histórico, em especial como seus princípios chegaram ao sistema educacional brasileiro.

\section{A NGP E O GERENCIALISMO EM EDUCAÇÃO}

De acordo com Dasso Junior (2014), Michel Messenet foi quem primeiro cunhou a expressão "Nova Gestão Pública", em sua obra La Nouvelle Gestion Publique: pour un Etat sans Burocratie ${ }^{3}$, publicada em 1975, em que critica a Administração Pública burocrática. Entretanto, o mesmo autor considera como seu texto fundador o artigo "A public management for all seasons?", escrito por Christopher Hood, publicado em 1991. Apesar de a NGP ter ganhado maior força no mundo a partir das últimas décadas do século passado, as críticas ao Estado de Bem-Estar Social, utilizadas como principais argumentos para a defesa

4 Uma gestão pública para todas as estações (tradução livre dos autores). 
do gerencialismo no setor público, começaram no final dos anos 1970 e início dos 1980, impulsionadas pelas crises daquele momento e pela emergência da globalização.

Para Mendes e Teixeira (2000), nas últimas décadas do século XX, o gerenciamento dos serviços públicos foi abandonando os sistemas baseados na hierarquia burocrática para adotar sistemas mais diversificados. $\mathrm{Na}$ base dessas mudanças, encontra-se o Novo Gerencialismo como tendência hegemônica influenciando concepções e práticas organizacionais dos serviços públicos, incorporando, nesse setor, a lógica concorrencial, em que o 'empreendedorismo' é tomado como a força propulsora das mudanças. Tendo como paradigma o mercado, estimula-se a realização de parcerias entre agências públicas e privadas e se introduzem inovações gerenciais, como, por exemplo, programas de qualidade total.

Esses mesmos autores tomam o conceito de Novo Gerencialismo de Clarke e Newman (1997), que o tratam como o conjunto de regras e normas que transcende os limites das organizações, correspondendo ao modo como uma instituição é incorporada em estruturas e processos organizacionais. Entretanto, esses autores advertem que os fundamentos teóricos que dão suporte às ideias do Novo Gerencialismo encontram-se nas abordagens do novo institucionalismo (Clarke; Newman, apud MENDES; TEIXEIRA, 2000, p. 3).

Sendo assim, pode-se afirmar que, se do ponto de vista político as bases da NGP se encontram na crítica ao Estado de Bem-Estar Social, ao planejamento centralizado e ao papel indutor e promotor do bem social exercido preponderantemente pelo Estado, suas bases epistemológicas estão no Novo Institucionalismo.

De acordo com Andrews (2005, p. 271), o Novo Institucionalismo pode ser considerado uma das abordagens teóricas mais influentes na ciência política contemporânea, em especial nos estudos sobre políticas públicas. O pressuposto básico dessa linha teórica é a ideia de que as instituições afetam o comportamento de atores sociais. Apesar dessa orientação teórica geral, o Novo Institucionalismo reúne diferentes argumentos, cada qual assumindo pressupostos específicos. Ainda segundo essa orientação, desde a publicação do trabalho clássico de Hall e Taylor (1996), considera-se que "o Novo Institucionalismo possui pelo menos três abordagens: o institucionalismo histórico, o de escolha racional e o sociológico (também referido como o da teoria das organizações)". (ANDREWS, 2005, p. 271).

A mesma autora observa que a abordagem do Novo Institucionalismo surgiu, de acordo com Immergut (1998, p. 28), como uma crítica ao behaviorismo, que aceita a ideia de que a soma das preferências individuais explica o 
comportamento coletivo. Contra essa concepção, os institucionalistas afirmam que a ação social é determinada por instituições, e não meramente pelo somatório das preferências. Alerta, porém, que, por outro lado, os institucionalistas também rejeitam o estruturalismo, o qual atribui a uma determinada estrutura social a força causal de todas as situações sociais. Observa ainda que a abordagem da escolha racional assume os mesmos pressupostos da teoria da escolha pública, "uma vez que se limita a um conceito de ação voltada para a realização de determinados fins, na qual atores se relacionam com os demais sujeitos como se fossem 'objetos' a serem utilizados como meios" (ANDREWS, 2005, p. 274).

Desse modo, a NGP surge em contraposição à Administração Pública, buscando influenciar novos modos não só de organizar e gerir a coisa pública, mas também novos modos de governo, já que ela interfere nos objetivos da ação pública.

Mendes e Teixeira (2000), buscando compreender as diferenças de abordagem entre a Administração Pública e a New Public Management (NPM), ou NGP, afirmam que a primeira parte do pressuposto de que, no processo político de tomada de decisão, uma melhor resposta sobre como decidir o que fazer é buscada mediante a interpretação de dados obtidos em cenários alternativos. Com relação à mesma questão, o NPM parte do pressuposto de que não existe uma melhor resposta, mas "uma só resposta que sobrevive ao processo político" (HUGHES, 1998 apud MENDES E TEIXEIRA, 2000: pag. 4). A abordagem dedutiva assume que existem bens que podem ser maximizados por pessoas, de modo que predições podem ser feitas sobre seus comportamentos, cujo objetivo é maximizar os benefícios. Ou seja, no que se refere à tomada de decisão, os pressupostos utilizados pela Administração Pública e pela NPM são diferentes. Os autores concluem que o sentido dado pelo Novo Gerencialismo às inovações gerenciais é a introdução, nos diversos níveis do setor público, de mecanismos de mercado e a transferência, para esse setor, do conjunto de ideias, valores e técnicas predominantes no setor privado.

Assim, a NGP se instala como inovação, criticando a burocratização dos Estados de Bem-Estar Social mesmo onde não se chegou a vivê-lo de fato, como na região latino-americana, promovendo ataques às hierarquias, à centralização do poder e das decisões, à rigidez das estruturas governamentais, o que encontra muita acolhida junto à opinião pública. O funcionalismo passa a ser altamente criticado como ineficiente e pouco comprometido, o que o coloca no centro dos ataques ao modelo de organização estatal.

Alber (2013), analisando a implantação da NGP no contexto francês, constata que os ataques principais são dirigidos, sobretudo, à gestão da carreira, opondo-se com forte resistência às estruturas tradicionais e estimulando uma 
lógica de distribuição individualizada que promove mecanismos gerenciais utilizados pelas empresas privadas: individualização de salários, com indexação de desempenho definida por objetivos quantificados; individualização dos percursos com maior mobilidade, negociados durante as avaliações. Ainda segundo ele, essa lógica é especialmente disseminada entre o pessoal de gestão, com base em incentivos que mobilizem conjuntamente a busca de utilidade (benefício material individual imediato ou diferido) e prevenção de riscos (medo de sanções). Estão presentes ainda uma contratualização cada vez mais precisa nos requisitos recíprocos do empregador e do empregado, com períodos de compromisso cada vez mais curtos, defendida como a única maneira de garantir uma eficiência operacional ideal. Dentro de uma empresa, essa lógica de mercado promove o questionamento permanente das posições adquiridas, para permitir a promoção acelerada dos funcionários mobilizados e a marginalização daqueles que, devido a limite de idade, ou a um efeito de desilusão, tendem a moderar seu investimento ou a perder eficiência.

A introdução da NGP na educação tem seus primeiros registros na realidade britânica, com a reforma dos anos 1980, com repercussões diretas sobre a gestão da escola (GEWIRTZ; BALL, 2011), mas sua disseminação em âmbito internacional se deu a partir dos anos 1990.

Grimaldi, Serpieri e Taglietti (2015), referindo-se ao caso italiano, afirmam que no final dos anos 1990, sob pressões da Organização para a Cooperação e Desenvolvimento Econômico (OCDE), a reforma da governança do sistema educacional tornou-se uma prioridade naquele país. Para os autores, essa orientação foi introduzida com base no argumento de que a forma de regulação centralizada da educação e do profissionalismo burocrático produzia organizações rígidas, ineficazes e autorreferenciais, que não eram: a) capazes de interpretar e responder às necessidades educacionais de uma economia de conhecimento, mercados de trabalho globais e competitividade global, comunidades locais e alunos; b) eficazes na promoção da qualidade do capital humano; c) comprometidas com o aprimoramento e melhorias. A quebra do sistema burocrático e hierárquico em organizações independentes, atuando em um ambiente descentralizado, foi identificada como estratégia de desagregação, para modernizar o sistema, torná-lo mais eficiente e responsivo às necessidades da sociedade e, por fim, para elevar seu desempenho. Para esses autores, numa virada ortodoxa da NGP, a mescla entre autonomia, responsabilização (prestação de contas), técnicas de gestão do setor privado, concorrência (imitativa) e um sistema de incentivos foi evocada como estímulo para a eficiência, eficácia e aprimoramento.

Verger e Normand (2015) observam que nos últimos anos a NPM tem penetrado com força a agenda educativa global, por ser este um setor com 
destacada dotação orçamentária. Afirmam, ainda, que, onde foi aplicada, a NPM alterou de maneira drástica a forma como se concebe a governança das instituições educativas, já que princípios como a autonomia escolar, a prestação de contas, a gestão baseada em resultados e a liberdade de escolha escolar têm penetrado profundamente em como se regulam, proveem e financiam os serviços educativos.

As reformas realizadas no Brasil a partir dos anos 1990, que tiveram como orientação a NGP, sob o argumento da racionalidade técnica e de atribuição de maior eficiência ao setor público, introduziram mecanismos de gestão e organização escolar que corroboraram a deterioração das condições de trabalho, da carreira e da remuneração dos docentes (OLIVEIRA, 2015a). Alguns desses mecanismos têm sido impostos por medidas de flexibilidade da legislação trabalhista, dando maior liberdade à contratação temporária dos professores e permitindo maior diversificação salarial.

Entretanto, esse processo ocorreu de forma bastante diferenciada entre os estados e municípios. Ao mesmo tempo que as escolas passaram a ter maior autonomia por meio da gestão democrática, passaram a conviver com estratégias e ferramentas de controle e regulação por meio da avaliação externa com vistas à maior eficiência nos resultados. Nesse período, assistiu-se a uma importante ofensiva de programas empresariais no contexto escolar variando desde modelos da "qualidade total" até as parcerias empresa e escola (OLIVEIRA, 2010). As direções escolares sofrem diretamente essas influências e interpretam essas políticas de maneira variada, dependendo do perfil do ocupante do cargo até das condições objetivas da escola.

\section{OS PRECEITOS NORMATIVOS QUE ORIENTAM A GESTÃO EDUCACIONAL E O PERFIL DO (A) DIRETOR (A) ESCOLAR}

Qual o entendimento dos (as) diretores (as) escolares sobre o que ocorre no contexto político nacional e educacional e quais suas reais capacidades de interpretar as demandas que chegam às escolas são questões frequentes que se colocam entre os que discutem a gestão educacional. A crença de que quanto mais alto o nível de escolarização dos sujeitos, maior é sua capacidade de interpretar o mundo nem sempre é verificada. Ainda assim, o primeiro passo é saber quem são os sujeitos que ocupam os cargos de direção escolar e quais os preceitos normativos que regulam a gestão educacional. 
Com base em dados oficiais gerados a partir do questionário aplicado aos (às)diretores (as) na Prova Brasil de $2015^{5}$, disponibilizados pelo Instituto Nacional de Estudos e Pesquisas Educacionais Anísio Teixeira (Inep), buscouse traçar o perfil demográfico, socioeconômico e profissional desses indivíduos. Aliado ao levantamento da legislação concernente à gestão, tanto no governo federal, como nos estados e capitais integrantes da pesquisa, no período de 2003 a 2015, procurou-se, ainda, confrontar o perfil obtido com os dados das escolas das cinco capitais, com o intuito de verificar em que medida a amostra reflete a predominância do perfil geral.

A gestão democrática do ensino público é definida como princípio no artigo 206 da CF/1988, reafirmada, assim, na Lei de Diretrizes e Bases da Educação Nacional (LDB no 9.394/96), em seu artigo terceiro, inciso VIII, nos mesmos termos da CF/1988, embora a referida lei acrescente a expressão: "nos termos desta lei, e da legislação dos sistemas de ensino, estabelecendo, portanto, que leis específicas deverão dispor sobre ela.

O Plano Nacional de Educação (PNE) 2014-2024 (Lei nº 13.005/2014) também estabelece diretrizes sobre a gestão escolar. No inciso VI do artigo segundo, que define os princípios da educação, está prevista nos seguintes termos: "Promoção da gestão democrática da educação pública". O artigo 9 da mesma Lei prevê:

Os Estados, o Distrito Federal e os Municípios deverão aprovar leis específicas para os seus sistemas de ensino, disciplinando a gestão democrática da educação pública nos respectivos âmbitos de atuação, no prazo de 2 (dois) anos contados da publicação desta Lei, adequando, quando for o caso, a legislação local já adotada com essa finalidade (LDB, 1996).

É importante considerar, ainda, que a LDB/1996 estabelece a gestão escolar como função do magistério, assim expressa no $\int 2^{\circ}$ do artigo 67 :

São consideradas funções de magistério as exercidas por professores e especialistas em educação no desempenho de atividades educativas, quando exercidas em estabelecimento de educação básica em seus diversos níveis e modalidades, incluídas, além do exercício da docência, as de direção de unidade escolar e as de coordenação e assessoramento pedagógico, se exercida em estabelecimento de educação básica em seus diversos níveis e modalidades (LDB, 1996).

Os(as) diretores(as) escolares podem ser, de modo geral, segundo os documentos que se referem aos parâmetros da gestão educacional: os(as) professores(as) que atuam na Educação Básica e especialistas em educação.

5 Os dados referem-se aos questionários socioeconômicos respondidos pelos (as) diretores (as) que atuam em estabelecimentos que ofertam o Ensino Fundamental com um número superior a 20 alunos matriculados no $5^{\circ}$ e $9^{\circ}$ anos. 
De acordo com os dados da Prova Brasil (BRASIL, 2015), a gestão escolar nos estabelecimentos de ensino público abrangidos no estudo é realizada, basicamente, por diretores (as) que são, em sua maioria, do sexo feminino (80,9\%), com idade entre 40 e 49 anos (42,9\%) e autodeclarados brancos (49,7\%). São profissionais com formação em nível superior (96,9\%) concluída há, no máximo, 14 anos (55\%) e em cursos de formação de professores (Pedagogia, Normal Superior ou Licenciatura) realizados, em sua maioria, em instituições de ensino privadas $(58,3 \%)$ e em cursos presenciais $(82,1 \%)$. Entre os (as) diretores (as) que afirmaram ter concluído o ensino superior, $85,3 \%$ indicaram ter feito algum curso de pós-graduação, com preponderância do tipo lato sensu (81,9\%).

A maioria desses profissionais possui experiência em educação de mais de 15 anos. Destaca-se, inclusive, que mais da metade desses indivíduos (50,9\%) tem tempo de trabalho suficiente, ou aproximado, para requerer aposentadoria. Contudo, apresentam uma experiência na função de diretor (a) relativamente pequena; 63,8\% deles informaram ter tempo de atuação na função de direção de até cinco anos. Para aproximadamente $3 / 4$ dos (as) diretores (as), esse mesmo intervalo representava sua atuação na mesma UE.

Os estados e capitais amostrados cumprem as determinações da legislação nacional sobre a gestão educacional, porque têm órgãos municipais ou estaduais de educação, secretarias, conselhos estaduais ou municipais de educação e suas escolas elaboram o projeto pedagógico. Além disso, todas as escolas das redes pesquisadas têm Colegiado/Conselho Escolar, composto por integrantes da comunidade escolar.

Entretanto, o propósito de uma "gestão democrática" expresso na legislação educacional depende de grande esforço. A Meta 19 PNE 2014-2024 (BRASIL, 2014) reflete a importância atribuída na agenda política atual aos diretores escolares, ao buscar regular, por meio de um mecanismo nacional de prova técnica, aqueles que ocuparão tal função nos milhares de estabelecimentos escolares brasileiros. Além disso, visa a assegurar, em um prazo de dois anos, já passados e não cumpridos, condições para efetivação da gestão democrática da educação, associando-a, dentre outros aspectos, à consulta pública à comunidade escolar. Apesar disso, grande número de diretores (as) chegam a esse posto mediante formas questionáveis do ponto de vista da proposta da gestão democrática (mais de 50\%, nos estados, são preenchidos por indicação política). 


\section{A NGP E AS DIREÇÕES ESCOLARES: O QUE DIZEM AS ENTREVISTAS}

Os dados obtidos nas entrevistas com diretores(as) das UE amostradas foram submetidos a tratamento analítico específico, por meio de programa de análise qualitativa (NVivo), a partir de categorias-chave selecionadas após revisão de literatura, sendo elas: condições de trabalho; relação de poder (presença de conflitos); percepções sobre a gestão escolar; motivações para o exercício da gestão; concepção de educação (ensino); concepção de justiça social e de justiça escolar; compreensão e definição do termo qualidade em educação; preocupação com os resultados escolares; preocupação com o futuro dos alunos; estratégias de ação para atingir os objetivos (metas).

\section{CONDIÇÕES DE TRABALHO E PERCEPÇÕES SOBRE A GESTÃO}

Observa-se que os (as) diretores (as) atuam no limite da relação entre os recursos disponíveis e as condições objetivas para a oferta educacional, especialmente em UE que apresentam condições estruturais precárias, localizadas em regiões de vulnerabilidade social.

Nas entrevistas são recorrentes as afirmações sobre as condições estruturais precárias das UE, com relatos de espaço de trabalho reduzido e provisório, e a necessidade de compartilhamento deste com diferentes profissionais e públicos. Em Goiânia, uma das UE pesquisadas estava em vias de encerrar suas atividades após a mudança de prédio, devido a obras viárias projetadas para passar pelo espaço da antiga escola. Segundo sua diretora, o novo espaço de funcionamento da UE fez reduzir o atendimento de 700 para 200 estudantes, em um local onde funcionava uma escola técnica.

\footnotetext{
Aqui é uma escola de formação profissional curta, do estado também. Aí nos cederam algumas salas e estamos aqui porque, como não foi autorizado fazer novas matrículas, o número de alunos está caindo [...] A comunidade está procurando os meios de comunicação e parece que nem a televisão está mais atendendo. Os pais ligam: "olha a escola está acabando" (Diretor/a de escola da rede estadual de educação de GO).
}

A principal queixa se relaciona às condições objetivas para o desenvolvimento do trabalho pedagógico e à insuficiência de funcionários para atender a demanda. $\mathrm{Na}$ visão dos (as) entrevistados (as), tais aspectos têm impacto direto no trabalho dos professores e em sua satisfação profissional e, 
consequentemente, colocam os (as) diretores (as) no centro do conflito: ante a comunidade escolar, que busca resposta às suas necessidades e diante do poder público, que não atende com eficiência às demandas e exige o cumprimento das metas preestabelecidas.

\begin{abstract}
Essa questão estrutural influencia muito no atendimento. As pessoas ficam mais estressadas, mais cansadas porque exige mais delas. [...] E o que acontece muitas vezes? A pessoa vai querer colocar a culpa em alguém por essa questão. Quem é o responsável por isso? Eu sei que não sou eu, mas será que todo mundo sabe que não sou eu? Até que ponto eu tenho responsabilidade sobre isso? (Diretor/a de Centro Municipal de Educação Infantil em Goiânia).
\end{abstract}

Os depoimentos deixam transparecer a centralidade de seu papel no cotidiano escolar, desempenhando uma função de mediação entre os diversos atores. Para eles, o (a) diretor (a) escolar se coloca como verdadeiro "articulador" e "mediador de conflitos". Ao mesmo tempo que é responsável pela gestão dos recursos financeiros e materiais da instituição, tem que gerir as relações sociais da escola. Torna-se, de um lado, a voz dos atores presentes no chão da escola e, de outro, a personificação do Estado.

Tanto faz em uma escola grande ou em uma escola pequena se você trabalha com meia dúzia de professores que pensam diferente de você, você tem que trabalhar; às vezes, você tem que fazer intervenção até nas famílias, no convívio familiar, nos pais [...] então, quando tem um conflito interno ou familiar, eu sou chamada para mediar (Diretor/a de escola da rede estadual de ensino de GO).

É nessas condições adversas que os (as) diretores (as) enfrentam os desafios de mediar conflitos, improvisar situações propícias aos ambientes de aprendizagem e realizar justiça social, ao mesmo tempo que devem cumprir as metas de eficiência de seus sistemas escolares definidas pelos governos.

\title{
ESTRATÉGIAS DE AÇÃO DOS(AS) DIRETORES(AS) PARA ATINGIR OS OBJETIVOS
}

A gestão das escolas pesquisadas se dá de modo compartilhado, embora a maior carga de trabalho e responsabilidade recaia sobre a direção. Em geral, eles (as) contam com uma equipe que os (as) auxilia nas tomadas de decisão, processos de compras e prestação de contas. Mas há queixa pelo número insuficiente de funcionários. Algumas UE têm à disposição um setor de finanças e tesoureiros (as) ou, ainda, responsáveis diretamente pela gestão da merenda escolar, como é o caso da rede estadual de ensino de Minas Gerais. 
Os conselhos que deveriam ser instâncias apoiadoras dessas gestões, apesar de serem citados como participativos, carecem, como no caso da representação de pais, de conhecimento acerca das necessidades das escolas.

A questão [...] ele é atuante, mas não são pessoas que dão muitas ideias não. Porque a gente trabalha muito dentro de orçamento. Então, hoje, por mais que tenham projetos, você não tem o financeiro para realizá-los. Então, esses pais vêm, falam uma coisa, falam outra, tentam ajudar, apoiam ou não, se vai adquirir isso ou não. Mas, assim, dizer que vamos criar coisas novas, ele não tem tanto esse acesso porque estamos limitados ultimamente nas finanças mesmo (Diretor/a de escola da rede estadual de ensino de $M G$ ).

Dentro das possibilidades, mostraram-se relevantes instrumentos de legitimação das ações da gestão escolar, sobretudo com relação ao plano de aplicação dos recursos, por serem instância consultiva e respaldarem as decisões dos (as) diretores (as).

Uma percepção paradoxal de autonomia pode ser observada na fala dos (as) diretores (as) no que diz respeito ao controle sobre seu trabalho e ação política. Ao mesmo tempo que afirmam ter certo grau de autonomia para tomar decisões, admitem receber dos órgãos competentes orientações determinadas, que limitam seu campo de ação; um paradoxo que parece ter a ver com sua prática e o local que ocupam no sistema de relações que passa pela comunidade local e o poder público. Em outros casos, colocam-na como empecilho na tomada de decisões importantes que refletem na qualidade do ensino.

As situações burocráticas sempre estão vinculadas às unidades; [...]a gente não tem uma autonomia plena. Dizer que a gente tem uma autonomia plena, a gente não tem. Porque tem situações que, para nós decidirmos, a gente precisa verificar com a gestora no caso. Está acontecendo tal e tal situação assim, a gente vai precisar de um respaldo dela para que a gente possa agir. Então, essa autonomia plena, a gente verdadeiramente não tem (Diretor/a de escola da rede estadual de ensino do PA).

Essa autonomia limitada guarda relação com a responsabilização e autorresponsabilização dos (as) diretores (as), que se sentem cobrados tanto pela gestão dos recursos, quanto pelos resultados acadêmicos dos alunos.

Controle em cima de resultados. Se acontece alguma coisa errada, sempre tem a fiscalização, sempre tem, digamos, que ficar consertando [...] Prestação de contas, Ideb, relatório, questões de matrícula. Questões de turma. [...] o setor aqui mais próximo sempre está cobrando os relatórios, que a gente tem que mandar um mensal (Diretor/a de escola da rede estadual de ensino do PR). 
Com relação às avaliações externas, destaca-se a inserção do conteúdo dos exames anteriores no planejamento do trabalho pedagógico, com vistas a preparar os alunos para os próximos testes, ainda que haja resistência por parte de professores.

\begin{abstract}
O que nós fazemos para melhorar o desempenho do aluno? Nós pegamos os conteúdos anteriores e os professores trabalham aquilo ali. O que foi trabalhado em uma prova do Enem, do Ideb, do Saego, provas de avaliações externas, a gente pega o conteúdo e faz a presença no planejamento bimestral do professor. Aí eles trabalham [...] às vezes o professor fala [que] não vai dar o conteúdo, não preocupa com o conteúdo, preocupa com qualidade do conteúdo, foi o professor de geografia. Eu dei essas orientações [...] a gente já tinha as aulas de planejamento. Essa aula que foi tirada da Prova Brasil, o conteúdo está melhor que o planejamento [...] e trabalhar com ela, quem sabe se vai repetir na próxima prova (Diretor/a de escola da rede estadual de educação de GO).
\end{abstract}

Outras estratégias incluem a realização de atividades para maior envolvimento dos alunos e comunidade escolar no processo de realização das avaliações, como atividades em grupo ou, até mesmo, uma "merenda diferenciada":

\begin{abstract}
Nossa gerente regional, que é a [citou o nome da gerente], ela tem todo esse cuidado, "né", de fazer essa [organização] e incentivar a direção da escola. Então, eles fazem duas provas antes para fazer, tipo, um simulado [...] para que eles aprendam onde é que marca o X, como é, e faz uma preparação antes. Os professores debatem com esses alunos e, uma semana antes, a gente fica todos os dias lembrando, faz a contagem regressiva para o dia "D", faz uma merenda diferenciada para que venham, conversa com os pais a importância de eles participarem no dia da avaliação. Então, tem todo um trabalho para que no dia eles estejam preparados para fazer essa prova (Diretor/a de escola da rede municipal de ensino do Recife).
\end{abstract}

Constata-se que a grande estratégia é fazer com que os estudantes tenham um bom desempenho nos testes e, assim, as escolas possam atingir suas metas. Essa é a grande guilhotina que ameaça a cabeça das direções escolares.

\title{
AS MOTIVAÇÕES DOS(AS) DIRIGENTES ESCOLARES PARA O EXERCÍCIO DA GESTÃO E A PREOCUPAÇÃO COM OS RESULTADOS ESCOLARES DOS ALUNOS
}

Quanto às motivações para o exercício da gestão, destacam o desejo de fazer algo diferente pela melhoria da escola, a partir de suas insatisfações como docentes, sobretudo no que tange às condições de trabalho e à qualidade do ensino: 
Eu acho que eu estava insatisfeita com a forma que as coisas andavam, eu vi que eu podia, na direção, mudar a qualidade do ensino, incentivar mais meus colegas de trabalho já que eu era professora. E [vivia] a realidade deles, e sabia como a gente poderia melhorar, e é isso que eu tenho feito, tenho tentado melhorar sempre olhando para eles como um professor, que eu sou professora né. E dando, tentando dar essa qualidade para que eles possam ser melhores em sala de aula (Diretor/a de escola da rede municipal de ensino do Recife).

A preocupação com o desempenho dos alunos nas avaliações aparece em praticamente todas as entrevistas. Em muitos casos, essa preocupação está relacionada às possibilidades de vinculação do repasse financeiro das escolas ao desempenho que apresentam no Ideb, mas também a uma profusão de exames externos que chegam até a escola e que se traduzem em metas a serem cumpridas.

Os sistemas de ensino, ao terem metas de qualidade atreladas ao Ideb, passaram a direcionar a gestão das escolas de modo a se ocuparem com o desempenho dos estudantes em conteúdos específicos (português e matemática) mensurados pelas avaliações. Isso levou os/as dirigentes escolares a adotar estratégias de reforço escolar e simulados para o alcance das metas estabelecidas, deslocando, às vezes, o foco do projeto pedagógico para os resultados nas avaliações.

Ele [conteúdo] entra no planejamento e reforça o trabalho do professor para que o aluno seja bem sucedido na próxima prova. E nós temos também... o que a gente chama aqui de "as provas que não são" ... a gente repete muito esses conteúdos para se fazer o simulado. Nós temos o simulado e o simuladão. Simuladão é sempre em final de bimestre e o simuladinho, como a gente chama, pega o conteúdo que foi dado, que o professor trabalhou, inseriu no planejamento, que vem de fora, vem da secretaria. Esse conteúdo que não está melhor, então vamos trabalhar nele e aí, em cima desse conteúdo trabalhado, nós temos uma avaliação. Se o aluno não saiu bem naquele conteúdo, a gente [entra] com o conteúdo do planejamento de novo para reforçar, repetindo (Diretor/a de escola da rede estadual de ensino de GO).

Com o intuito de auxiliar os estudantes com dificuldades de aprendizagem a alcançarem bons resultados nas avaliações e, por conseguinte, aumentar o Ideb da escola, são utilizadas estratégias específicas como o acompanhamento individual dos estudantes.

Então, os professores de português e matemática dão aula de reforço. Eles trabalham a sexta aula com esses alunos, né? São poucos, que eles são alunos que não estão no projeto do Mais Educação, "né? (Diretor/a de escola da rede municipal de ensino do Recife).

Em contraposição à concepção de mensuração da eficiência escolar objetivada no Ideb, foi criado paralelamente, no mesmo ano 2007, pelo Governo 
Federal, o Programa Mais Educação (PME), com o objetivo de ampliar a jornada diária educativa de crianças e adolescentes, visando a diminuir as desigualdades educacionais com a oferta da educação integral. Ao contrário da noção de eficácia dos resultados presentes na política do Ideb, o PME foi implantado com vistas a uma educação plena e integral para crianças e jovens de baixa renda, no sentido de formar cidadãos emancipados. O PME também se tornou uma fonte complementar de recursos financeiros, tendo em vista que são as escolas mais precárias e de regiões mais vulneráveis a atender os alunos mais carentes. Essas políticas conviventes, mas em muitos aspectos contraditórias, estão no cotidiano da gestão escolar e apresentam desafios importantes.

São crianças carentes, que ainda precisam de muita ajuda.Tem criança que chega aqui, muitas vezes, sem tomar o café da manhã e, quando a gente vê essa situação, a gente dá o nosso jeito. Se a gente não tem merenda, a gente vai lá e compra um lanche e dá para a criança. Então a gente trabalha muito próximo a essa criança. Temos crianças que vêm de escolas particulares, que fizeram toda uma pré-escola, a educação infantil, que vêm da escola particular. Que os pais estão presentes, estão sempre presentes por aqui; mas têm outros que a situação socioeconômica [...] os pais trabalham como feirantes (Diretor/a de escola da rede estadual de ensino do $\mathrm{PA})$.

O PME foi pensado para introduzir no contraturno escolar atividades diversas (artes, esportes, lazer, etc.), buscando promover a educação integral dos estudantes. Porém as percepções do PME variam muito entre os (as) entrevistados (as) desde aqueles que de fato se sensibilizam com as necessidades do público-alvo e se envolvem com o programa até os que o tomam como mais uma ferramenta para alcançar os resultados do Ideb:

Tem! Até porque no Programa Mais Educação eles têm o acompanhamento pedagógico que é direcionado para português e matemática e, então, normalmente quando a gente se organiza para iniciar as atividades, os próprios professores titulares das turmas passam algumas informações do que estão trabalhando em sala de aula, quais seriam as dificuldades desses alunos, para que esses monitores, a partir desse mapeamento, possam também ajudar nesse sentido (Diretor/a de escola da rede estadual de ensino do PA).

Mesmo desenvolvendo várias estratégias para cumprir com as exigências de justiça social com a inclusão escolar dos estudantes num contexto orientado pela eficiência, relatam muitas dificuldades, dentre elas, a resistência dos alunos, a pouca infraestrutura, falta de participação da família, necessidade de atendimento especializado para crianças com deficiência, entre outros. Entretanto, essas críticas são trazidas também como aspectos que comprometem o alcance da meta estabelecida para a escola no Ideb. 
A gente tem essa dificuldade porque muitos não querem, a dificuldade da gente hoje é a resistência por parte deles não quererem ser inseridos, sabe. Eu tenho um menino que já reprovou. Ele não sabe ler e escrever. Existe uma professora aqui, ela está sentada aí, já falou com a mãe, já falou com ele, eu já pedi por tudo para ele vir, porque é no contraturno, né? Ele, simplesmente, rejeita. Ele não quer, não aceita e, durante a aula, ele não consegue produzir, né. Eu já chamei, já sentei do lado dele, [montei] uma atividade para ele, pedi para que ele fizesse, me mostrasse o que sabe, e ele, simplesmente, disse, "eu não sei nada". Eu disse "meu amor, veja, eu não sou alfabetizadora, isso eu não consigo fazer, mas eu estou te dando oportunidade, essa professora, ela é alfabetizadora, senta do lado dela". "Eu não quero". A resistência é muito grande. Então, hoje a gente pode dizer assim: 98\% dos nossos alunos são adolescentes normais de brincar, de perturbar, de fazer e acontecer, mas eles conseguem compreender, eles conseguem atingir a meta deles. Porém eu tenho poucos alunos que têm essa dificuldade; mas eles resistem, eles não querem aceitar, não querem ser inseridos. (Diretor/a de escola da rede municipal de ensino do Recife).

As entrevistas exprimem dificuldades para atender às orientações que chegam à escola sem muitas vezes problematizar seus fins, sem mesmo interpretálas. A preocupação em conciliar as exigências de inclusão presentes no PME se traduzem frequentemente em fazer com que essas crianças e jovens, acima de tudo, aprendam português e matemática. A naturalização da expressão "direito de aprendizagem" reduz o complexo processo educativo a um número, a um indicador que desconsidera importantes dimensões da personalidade humana e da vida em sociedade.

Existem exigências. Por exemplo, a gente precisa alcançar uma meta e, às vezes, a gente fica se preocupando: será que a gente vai montar o nosso plano de ação só para alcançar uma meta ou para garantir o direito de aprendizagem dos alunos? Existem políticas que a gente precisa de um respaldo maior, precisa de um apoio maior, a gente precisa de uma estrutura melhor e que a gente não tem. Então, quando as políticas vêm, elas vêm no sentido de exigir de nós o alcance de uma meta, mas, junto com essas políticas, não vem também uma perspectiva de melhoria da infraestrutura que é necessária (Diretor/a de escola da rede estadual de ensino do PA).

\section{A RELAÇÃO DO(A) GESTOR(A) EDUCACIONAL COM OS DEMAIS PROFISSIONAIS NA ESCOLA}

Quando perguntados(as) sobre sua relação com os demais profissionais da escola, são unânimes em afirmar que possuem boa relação, embora algumas manifestações da necessidade de manter uma postura mais antidemocrática esteja presente em alguns momentos. 
Olhe, eu gosto da minha relação com os professores porque eu sou professora, desde 2010 que eu estou aqui. Então, eu fazia parte do quadro de colegas. Aí, saí para a gestão da escola, eles me conhecem e eu conheço eles também como professores, entendeu? Sei o que é que eles fazem e eles também me conhecem. Eu acho, gosto, [...] a gestão ela tem que ser o exemplo. Se você não é exemplo, como é que vai cobrar alguma coisa que você não faz? Então, eu cobro muito a questão de horário, mas, antes de cobrar o horário deles, eu estou aqui no horário, entendeu? Eu tenho muito isso. Se eu vou cobrar deles, é porque eu já fiz primeiro. (Diretor/a de escola da rede estadual de ensino de PE).

As reuniões com os docentes são frequentes em seus relatos e são para discutir temas como o planejamento escolar, gestão dos recursos financeiros, comportamento dos alunos, elaboração de Projeto Político Pedagógico e Regimento Escolar, etc. Entretanto, foram apresentadas dificuldades em realizar as reuniões dentro do calendário escolar e de contar com a presença de toda equipe de profissionais. Os argumentos são, em geral, da necessidade de uma gestão participativa e compartilhada, baseada no trabalho coletivo e na participação ativa dos docentes nas decisões da escola.

Primeiro é ele (diretor) não tomar decisões solitárias, a gente não toma decisões solitárias. Sempre procura ouvir os vice-diretores, alunos, professores, coordenadores pedagógicos, para construir uma decisão. Decisões têm que ser coletivas, então é uma gestão participativa, e essa participação não se dá necessariamente em rodas de conversas, pode ser em conversas individuais com vários segmentos; família também, governo, acaba que a secretária de educação... a gente para tomar decisões tem que ser baseadas nas leis, nos nortes dados, esses diversos decretos, resoluções e.... Você vai ouvindo muito e aí você reúne condições para você tomar uma decisão. (Diretor/a de escola da rede estadual de ensino de MG).

Mas expressam, também, certo isolamento do cargo, momentos em que precisam assumir decisões e ações que seriam de responsabilidade de toda a equipe ou de pequenas comissões.

Quando vai fazer a eleição do conselho, a primeira coisa que a pessoa fala é “você vai resolver tudo?”, "eu não vou precisar ir lá né?!". Então, as pessoas não querem assumir essa função, que acaba que é a diretora [...] sou eu lá que assino essa documentação. Lá tem o espaço da tesoureira, mas sou eu que assino. Esse é o plano de aplicação, eu acabo assinando por ela. Todos são assim, todos, acaba tendo a assinatura só da diretora, por conta dessa dificuldade. (Diretor/a de Centro Municipal de Educação Infantil de Goiânia).

A mediação de conflitos entre os profissionais e entre docentes e alunos/ famílias também ocupa parte das atividades dos (as) diretores (as) e reflete certa concepção motivacional para lidar com os diferentes atores. 
Hoje, praticamente, nós só temos uma dificuldade na gestão em si: é que estamos vivendo um choque de geração. $O$ choque de geração cria uma relação um pouco conflituosa entre alunos e professores, professores e direção, direção e família. Acho que esse é o grande gargalo... Mas acho que também tem mais uma, acho que está chegando alguns profissionais, chegam muitos profissionais bons, mas estão chegando alguns profissionais agora que estão muito focados nos direitos e estão esquecendo dos deveres. [...] Então esse choque de geração tem dificultado sim a gestão. [...] Eu acho que a função do diretor muda. Óbvio que muda! Mas, quando você pensa no relacionamento humano, que é o foco principal, você tem que conseguir fazer com que essas diversas gerações, talvez uma ou duas gerações, consigam se entender. (Diretor/a de escola da rede estadual de ensino de MG).

A mediação de conflito entre os diversos sujeitos que participam do cotidiano escolar tem sido uma dimensão bastante recorrente na atuação dos (das) diretores (as). Esses sujeitos se veem cotidianamente diante do dilema entre prestar contas sobre os resultados esperados em cada meta e a necessidade de responder aos reclamos urgentes dos que não conseguem integrar-se a essa lógica.

\section{APONTAMENTOS FINAIS}

As mudanças no perfil da direção escolar, transitando de um tipo técnico e burocrático para uma liderança política ou gerencial, têm sido objeto de estudos em diferentes realidades (CATTONAR, 2006). Estudos também têm demonstrado que a necessidade de corresponder às expectativas tanto por parte do corpo docente e discente como ainda da administração tem implicado sobrecarga de trabalho desses profissionais (OLIVEIRA, 2002; SARUBI, 2008).

O redesenho da gestão escolar que vem se definindo com a introdução da NGP carece de maiores estudos, tendo em vista a diversidade de respostas e situações novas que são geradas por parte dos próprios sujeitos envolvidos. É necessário, ainda, levar-se em conta as especificidades locais, regionais e nacionais, compreendendo em que medida podem configurar-se como tendência internacional (CARTER; O’NEILL, 1995; BALL, 2002).

Como observa Derouet et Derouet (2010), a educação integrou, por longo tempo, o núcleo central do debate em torno do desenvolvimento e da justiça social a partir da noção de igualdade de oportunidades. A definição precisa dessa igualdade tem sido objeto de muitos debates, enquanto se observa o estabelecimento de uma relação direta entre a educação, o desenvolvimento e a questão social, que se apresenta, cada vez mais, como tarefa complexa. Nesse contexto, algumas políticas sociais exigem condicionalidades, a educação escolar aparecendo como uma dimensão importante no gozo dos direitos sociais. 
Nas últimas décadas, vimos crescer, não só no Brasil, mas em muitos outros países, as exigências de eficácia escolar, como influência de organismos internacionais (CARVALHO, 2009). São exigências de transformações, que repercutem na dinâmica escolar e na forma de atuação de professores e das direções escolares. De acordo com Dale (2009), as premissas da produtividade e da competitividade têm embasado as tendências internacionais de accountability ${ }^{6}$ ou benchmarking ${ }^{7}$, que constrangem os sistemas educativos ao empreendimento de ações no sentido de buscar, por meio de instrumentos de avaliação, a melhoria dos resultados escolares. Tais políticas chegam ao cotidiano escolar e influenciam diretamente a ação das suas direções.

Nesse contexto, a NGP vai sendo assimilada pelos gestores da educação pública, do ministério às escolas, perseguindo um Estado supostamente eficiente e dinâmico que busca mais resultados com menos emprego de recursos. Os princípios de eficiência importados da iniciativa privada vão sendo naturalizados como valores universais e já não se pergunta quais são as finalidades do público. No contexto escolar, essas orientações vão sendo assumidas como estratégias objetivas e pragmáticas que se apresentam não como forma de responder aos problemas, mas como a única resposta possível.

Os próprios sujeitos envolvidos diretamente na ação acabam por se ver como são descritos nos manuais que os instruem, como um verdadeiro "articulador" e "mediador de conflitos", "um exemplo", desdobrando-se para cumprir metas e objetivos sobre os quais nunca foram convidados a opinar.

\section{REFERÊNCIAS}

ALBER, A. Management et nouvelle gestion publique : limites et paradoxes de l'imitation du privé », La nouvelle revue du travail [En ligne], 2 | 2013, mis en ligne le 30 mars 2013, consultada em 10 de setembro de 2017. URL : http:// journals.openedition.org/nrt/934; DOI : 10.4000/nrt.934.

ANDREWS, C. W. Implicações teóricas do Novo Institucionalismo: uma abordagem Habermasiana. DADOS - Revista de Ciências Sociais, Rio de Janeiro, vol. 48, n. 2, p. 271-299, 2005.

6 Accountability é um termo da língua inglesa que pode ser traduzido para o português como prestação de contas com responsabilidade, o que remete à obrigação, à transparência, de membros de um órgão administrativo ou representativo de prestar contas a instâncias controladoras ou a seus representados. Este termo vem sendo largamente adotado em inglês em diferentes contextos nacionais e linguísticos.

7 Benchmarking consiste em indicadores de comparação de produtos, serviços e processos de trabalho que pertencem a organizações que evidenciam as melhores práticas sobre as distintas áreas de interesse, com ol propósito de transferir o conhecimento e disseminar as chamadas "melhores práticas" e sua aplicação. 
BALL, S. Reformar escolas/reformar professores eos terrores da performatividade. In: Revista Portuguesa de Educação. Universidade do Minho. 2002.

BRASIL. (1996). Lei no 9.394, de 20 de dezembro de 1996. Estabelece as diretrizes e bases da educação nacional.

BRASIL. (2014) Lei n. 13.005, de 25 de junho de 2014. Aprova o Plano Nacional de Educação - PNE e dá outras providências. Brasília/DF: Congresso Nacional, 2014.

BRASIL, MEC, INEP. Microdados da Aneb e da Anresc 2015. Brasilia: Inep, 2017. Disponível em: <http://portal.inep.gov.br/basica-levantamentos-acessar $>$. Acesso em: 30 out. 2017.

CARTER, D. S. G. ; O’NEIL, M. H. (Eds.). International Perspectives on Educational Reform and Policy Implementation. London: The Falmer Press. 1995.

CARVALHO, L. M.. Governando a educação pelo espelho do perito: uma análise do pisa como instrumento de regulação. Educação \& Sociedade, Campinas, vol. 30, n. 109, p. 1009-1036, set./dez. 2009

CATTONAR, B. Evolução do modo de regulação escolar e reestruturação da função de diretor de escola", Educação em Revista, 44, p. 185 - 208, 2006.

Clarke, J.; NEWMAN, J. The Managerial State: Power, Politics and Ideology in the Remaking of Social Welfare. 1997. 196 pag. 196. SAGE Publications. Thousand Oaks, CA

DALE, R. Os Diferentes papeis, propósitos e resultados dos modelos nacionais e regionais de educação. Educação \& Sociedade, Campinas, vol. 30, n. 108, p. 867-890, out. 2009

DASSO JUNIOR, A. E. “Nova Gestão Pública”: a teoria de Administração Pública do Estado ultraliberal. S/1, 2014. Disponível em: http://www. publicadireito.com.br/artigos/?cod=d05c25e6e6c5d489, acesso em 16/10/2014.

DEROUET, J. L. ; DEROUET, M. C. Repenser la justice dans le domaine de l'éducation et de la formation. Editiones Peter Lang- INRP. Paris. 2010. 
GESTRADO. Trabalho docente na Educação Básica no Brasil: Relatório Final da Pesquisa. Belo Horizonte: FAE/UFMG. 2010. 87 f. Relatório.

GEWIRTZ, S.; BALL, S. J. Do modelo de gestão do "Bem-Estar Social" ao "novo gerencialismo": mudanças discursivas sobre gestão escolar no mercado educacional. In: BALL, S. J. ; MAINARDES, J. (Orgs.) Políticas educacionais: questões e dilemas. São Paulo: Cortez, 2011, p. 193-221.

GRIMALDI, E.; SERPIERI, R.; TAGLIETTI, D.. Jogos da verdade. A Nova Gestão Pública e a modernização dos sistema educacional italiano. Educação \&. Sociedade, Campinas, v. 36, nº. 132, p. 759-778, jul.-set., 2015.

HALL, P. A. e TAYLOR, R. C. (1996), "Political Science and the Three New Institutionalisms". Political Studies, n XLIV, pp. 936-957.

HUGHES, O. E. Public Management and Administration: an introduction. 2nd ed. Austrália: Macmillan, 1998.

IMMERGUT, E. M. "The Theoretical Core of the New Institutionalism". Politics \& Society, vol. 26, no 1, p. 5-34, 1998. SAGE Publications. Thousand Oaks, CA

MENDES, V. L. P. S.; TEIXEIRA, F. L. C..O Novo Gerencialismo e os desafios para a Administração Pública. In: Encontro Anual da Associação Nacional dos Programas de Pós-Graduação 24, 2000, Santa Catarina. Anais eletrônicos... Santa Catarina: ANPAD, 2000. Disponível em: <http://www.anpad.org.br/ admin/pdf/enanpad2000-adp-341.pdf>. Acesso em: 21 set 2017.

OLIVEIRA, D. A Mudanças na organização e na gestão do trabalho na escola. In: OLIVEIRA, D.; ROSAR, M. (org.). Política e gestão da educação. Belo Horizonte: Autêntica, 2002.

OLIVEIRA, D. A. Mudanças sociais no Brasil no início do século xxi: políticas públicas em educação que fizeram a diferença. Revista Horizontes Latinoamericanos, v. 3, p. 37-47, 2015.

OLIVEIRA, D. A. Nova Gestão Pública e governos democrático-populares: contradições entre a busca da eficiência e a ampliação do direilto à educação. Educação \& Sociedade. Campinas, v. 36, n. 132, p. 599-622, jul./set. 2015a. 
OLIVEIRA, D. A. Educação básica: gestão do trabalho e da pobreza. 2. ed. Petrópolis: Vozes, 2010.

SARUBI, E. R.. Reformas educacionais e gestão democrática: repercussões dos diretores nas escolas municipais de Belo Horizonte. FaE/UFMG, 2008. (Dissertação de Mestrado).

VERGER, A.; NORMAND, R.. Nueva gestión pública y educación: elementos teóricos y conceptuales para el estudio de un modelo de reforma educativa global. Educação \& Sociedade. Campinas, v. 36, n. 132, p. 599-622, jul./set. 2015.

DALILA ANDRADE OLIVEIRA é Professora Titular de Políticas Públicas em Educação (UFMG). Pesquisadora PQ-1A/CNPq e PPM/FAPEMIG. E-mail: dalila@ufmg.br

ALEXANDRE WILLIAM BARBOSA DUARTE é sociólogo, mestre em Educação e doutorando do Programa de Pós-Graduação em Educação da UFMG. Bolsista da CAPES. Pesquisador do Gestrado. E-mail: duarte.awb@gmail.com

ANA MARIA CLEMENTINO é pedagoga, mestre em Educação e doutoranda do Programa de Pós-Graduação em Educação da UFMG. Bolsista da CAPES. Membro da Coordenação da Rede Estrado Brasil. E-mail: anamcjs@gmail.com 